\title{
Simulation of Ground-borne Vibration and Noise Due to High -speed Trains through Changsha Railway Station
}

\author{
SHEN Daoming ${ }^{1, a^{*}}, Z^{2 H A N G ~ L a i d o n g ~}{ }^{1, b}$, XUE Songtao ${ }^{2, c}$ \\ ${ }^{1}$ Department of Civil Engineering and Architecture, Xinxiang University, Henan, China, 453000 \\ 2 Department of Architecture, Tohoku Institute of Technology, Sendai, 982-8577, Japan

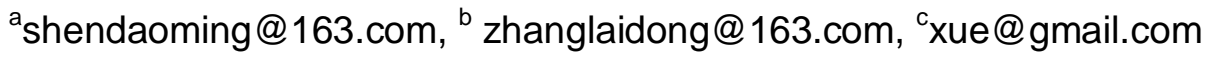

Key words: fast train; elevated train station; ground-borne noise; structure vibration

Abstract: Ground-borne vibration and noise induced by train operations are two major environmental problems faced by rail transit systems. Current researches mainly focused on civil architectures and bridge structures, but it is rare for large structures such as railway stations in most literatures. Within this framework, this paper presented an integrated predictive analytics to simulate the ground-borne vibration and noise due to high-speed train through Changsha railway station. This analytics obtains an accurate prediction of structure -borne noise by considering the fluid-structure interaction, based on excitation -spread- response finite element model of elevated station. The results show that this integration of predictive method is very effective.

\section{Introduction:}

With the rapid development of city rail traffic in our country, the people's demand on living environment is more and more high, effect of vibration on surrounding buildings along the train and ground-borne noise, has received growing public attention. Along the Shanghai subway, many residents made a complaint because of ground-borne noise within living environment. China has promulgated standards on the effects of ground-borne noise from evaluation construction projects related to prediction of subway, but designers need urgently the ground-borne vibration and noise in building structure induced by rail around or under construction, to modify the structure design of isolation or adopt the corresponding measures of reducing the noise, reduce the evaluation and retrofit of unnecessary waste. So the rail vibration and noise problems were paid more and more attention. Domestic and foreign scholars have already made a lot of research work. The National Academy of Sciences USA Transportation Research board and funded by the European Commission under the fifth Framework Program transport development plan (CONVURT) are currently being studied about the train vibration induced ground-borne noise.

According to the propagation loss method: source-communication-receiver, J. Melke[1] discussed the subway induced structural noise and vibration process.by using analytic method, the laboratory test and field test. With applying the finite element method combined with the Rayleigh integral vibration and geometric data using spatial easily combined with the finite element model and the boundary element model; A. B. Nagy[2] presented description of the acoustic field of the matrix, which is relatively small, no inverse, but the prediction accuracy is not high; G.. Degrande 
[3] used a three-dimensional numerical model to predict the ground-borne vibration and noise of structure induced by the subway, by coupling periodic finite element boundary element method to simulate the London subway Bakerloo line, predicted the three story frame structure assumed office of response and response; Using the boundary element hierarchical simulation field, finite element simulation of the upper structure, spectral finite element simulation noise calculation, P.Fiala [4]discussed ground-borne vibration and noise response of high-speed rail transportation on a regular frame office building, and three kinds of isolation measures were simulated test. According to the measured data to summarize the experience formula one indoor vibration, Kurzweil[5] proposed An empirical formula for radiation noise, because of the use of less parameter , the empirical formula is relatively simple, prediction of indoor noise can obtained roughly the approximate range of the ground-borne vibration and noise. The environmental impact assessment of the actual vibration data factors is complicated, rather than a specific vibration distribution. According to the foreign research, main documents concentrated on the propagation of the vibration, the subway environmental vibration prediction and reduction of noise. On the ground-borne vibration and noise, domestic studies is relatively few, mainly focus on the rail noise research, the general indoor structural noise prediction with experience formula to predict[6-8], the vibration and noise of the elevated train station researches is relatively little. In view of this, this paper investigate fast trains vibration on Changsha railway station waiting hall, puts forward an integrated analysis method in the prediction of elevated station. The finite element vibration spread response model based on this method, by considering the dynamic coupling analysis to realize the forecast of ground-borne noise. Analysis results show that the integrated predictive validity analysis method.

\section{Establishment of structure model}

\section{Engineering background}

The new elevated train station in Changsha is underground station layer frame structure, height $10.5 \mathrm{~m}$, composed of concrete filled steel tubular columns supporting a huge box girder; the first layer is the platform layer, layer height $9.25 \mathrm{~m}$, as the train through the layer: two layer is elevated, with two perpendicular to the trajectory of the waiting hall, the average height about $18 \mathrm{~m}$, profiled steel sheet concrete double floor waiting room floor for giant steel truss beam supporting the roof; wave shaped space truss structure. Because the station hall is located in the second layer, just below the rail in the waiting hall. while the train is running vibration through the air and structure will be spread to the waiting hall, waiting hall for passengers to cause vibration and noise. This paper mainly studies the influence of vibration of train passing through the station on the waiting hall and to induce ground-borne noise.

\section{Finite element model.}

The train station model is established mainly by 3D3S spatial structure design software and the ANSYS software, can be between two kinds of software model is no interface conversion.3D3S is the Tongji University independently developed CAD series software, operating platform, parameter setting simple component directly, has unique advantages of CAD and build the line unit; ANSYS-APDL has its unique advantage in establishing rules of the finite element model, can make up for the 3D3S in the building facade element on the disadvantages, and ANSYS has strong ability for finite element computation. 


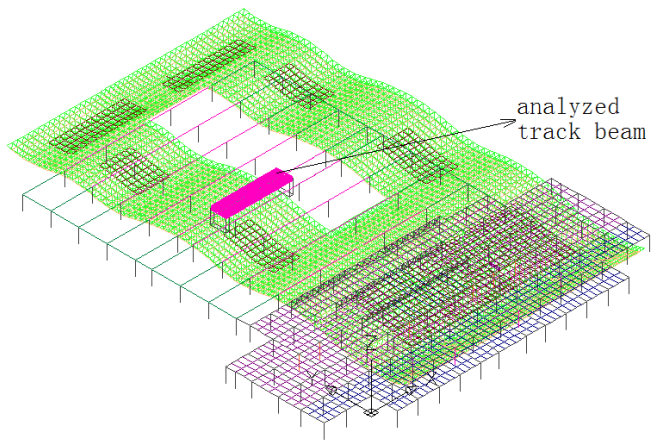

Fig.1 3D3S spatial structure mode

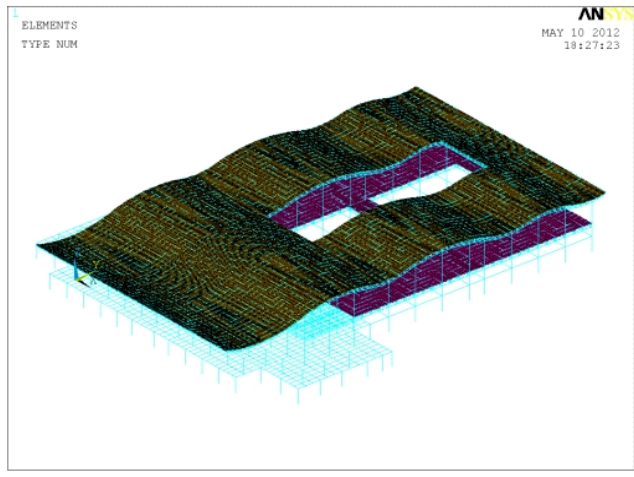

Fig. 2 FEM mode

The rapid establishment of bottom layer and a layer of irregular application of 3D3S concrete beam column structure and mega truss structure, the overall structure of the roof space truss type assembled 3D3S will establish the ANSYS, and then lead to the ANSYS assembly model, add the plate element in ANSYS, the whole model as shown in Figure 2, the beam column model beam44 and beam 4 unit, track beam and huge steel truss by beam44 unit, the roof and the floor with shell63 elements, each column section parameters of steel tube concrete with equivalent value, damping is the Rayleigh damping.

\section{Analysis of results}

\section{The train excitation force}

In this paper the calculation of exciting force main reference parameters of Shinkansen trains and tracks[9], the finite element model by 10 degree of freedom vehicle model, the rail, ballast bed simplified continuous elastic beam is composed of spring and damper, and considering the influence of train vibration, the ratio (Derby) of track irregularity spectrum. The train, rail, ballast bed as a vibration system, calculation of elevated station excitation force time history.

The exciting force of a sleeper to produce 12 cars with the speed of $162 \mathrm{~km} / \mathrm{h}$ is shown in Figure 3 (Fr) curve. With the assumption that the orbit is infinite, so after the train vibration force each sleeper of the shape of the curve is the same, the only difference is the presence of a time each adjacent sleepers incentive, this difference can simulate the train running on the track.

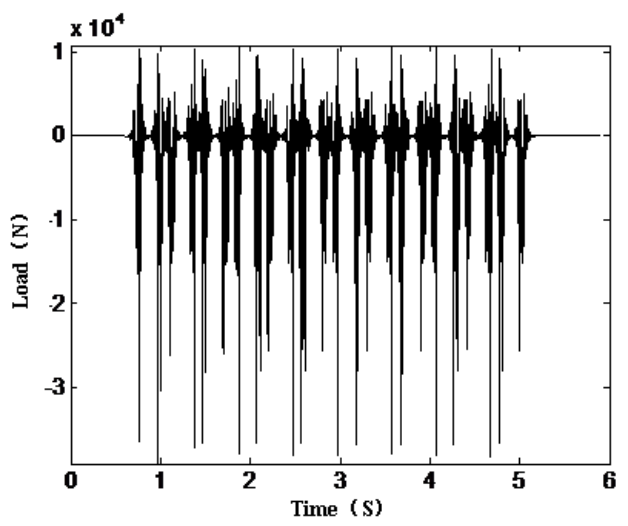

Fig.3 The exciting force

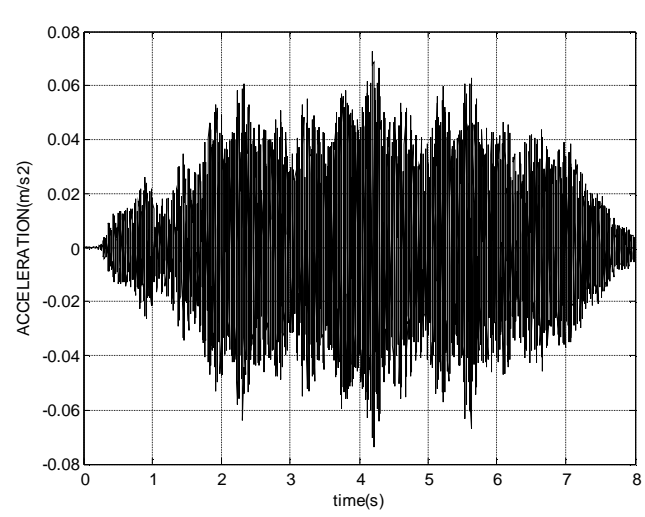

Fig.4 acceleration history of waiting room floor 


\section{Vibration analysis}

Select a three cross track beam which, set a loading point according to the actual sleeper spacing interval of $0.625 \mathrm{~m}$, the time history of sleeper vibration force Fr by train through each load point time difference in loading, through the ANSYS simulation of train loads excitation of track beam is calculated by, waiting hall floor vibration. Choose one side the waiting room is focus on the analysis of regional, extracts from the center line of the track of acceleration time history (Figure 4), the vibration time history response load can be seen near the large waiting room floor, the train induced vibration size decreases with increasing the distance from the center line of the track, the maximum acceleration response for the $0.08 \mathrm{~m} / \mathrm{s} 2$.

Figure 5 shows the 1/3 octave for different distances from the center line of the track in waiting room, as it shows: the vibration of waiting room on the frequency range of $100 \sim 150 \mathrm{~Hz}$ excitation for the response is relatively large, the maximum response value of approximately $86 \mathrm{~dB}$. So high frequency sound should be attenuation.

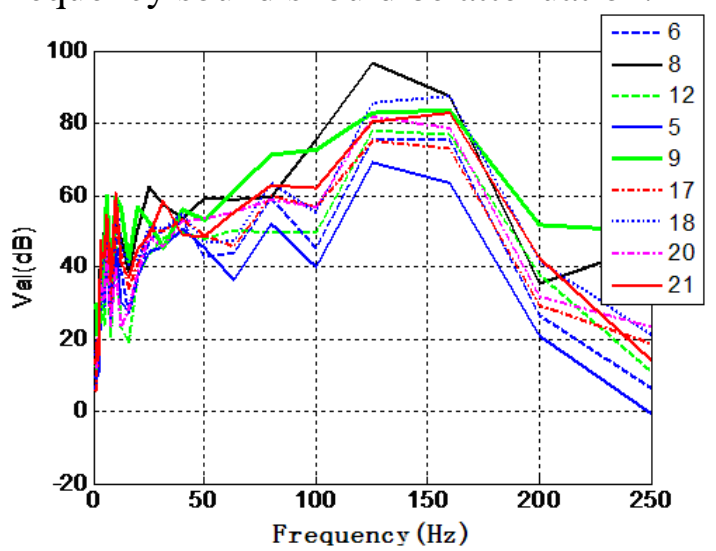

Fig.5 1/3 octave for vibration in waiting room

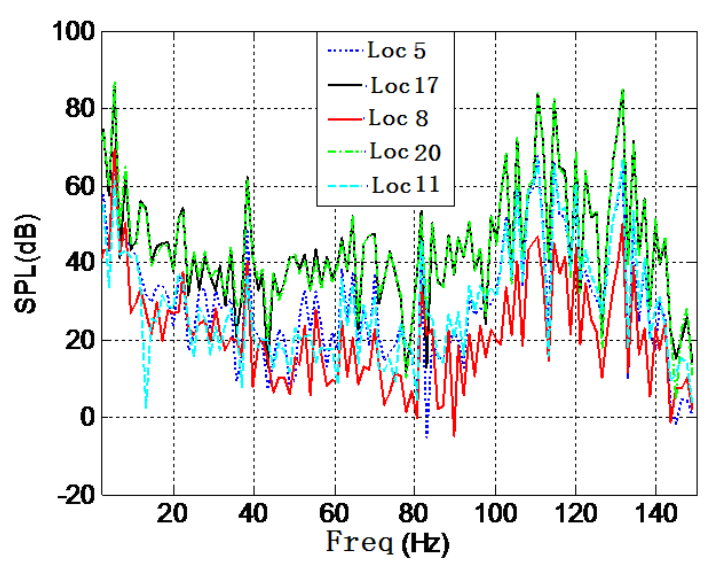

Fig.6 ground-borne noise in waiting room

\section{Noise analysis}

The spectral finite element method[10] is a method of acoustic modal superposition application room space. The sound pressure can be calculated by the analytic method of acoustic mode, it does not need to mesh, therefore discrete errors are avoided, the accurate calculation result can be achieved. Can handle with impedance boundary shape of wall sound absorption problems of spectral finite element method, for the lower wall sound absorption and the wall uniform impedance, direct boundary can also be deduced from internal pressure points.

The waiting hall is simplifid into a closed cavity, the curved truss roof is simplified into plane, the average roof height is taken the original roof height value, cavity length, width and height is 190m, 64m and 18m, closed cavity around each acoustic coefficients according to the actual value. The results of numerical simulation are in after the train station. Time history response, using Fuliye transform domain results are transformed into the frequency results. By using the spectral finite element method, using the two floor excitation, simulation of cavity noise response.

Through the analysis of results can be seen: the two noise train produced mainly occurs in the low frequency stage, the maximum pressure is about $69 \mathrm{~dB}$, slightly higher than the JGJ /T 170 2009 specifications; due to the impedance of structure and air, the high frequency should be attenuation.

\section{Conclusion}

Vibration based on fast train may have on Changsha elevated station waiting hall and ground-borne noise problems, analysis method is proposed to predict integration. The numerical 
results show the effectiveness of the method. The results are as follows:

(1) The method proposed in this paper integrates the moving train station generates vibration and noise on elevated train two times of simulation method of finite element, using the method of modeling combined with 3D3S and ANSYS to build large elevated station model is relatively complex, and solve the difficult to build large-scale complex system dynamic finite element model of finite element software problems.

(2) This paper proposes a time phase difference loading mode simulation of train vibration on the structure, avoid the same phase loading analysis results of low precision problem.

(3) Finite element elevated station source spread response model based on this method, and the spectrum analysis of finite element method to calculate the two radiation noise of high speed train caused by indoor, and predict the ground-borne noise.

\section{Reference:}

[1] Melke.J. Noise and Vibration From Underground Railway Lines: Proposals for a Prediction Procedure [ J ] J. Sound Vib, 1988, 120( 2),391 - 406.

[2] A.B.Nagy , P. Fiala , F.Marki, et al . Prediction of Interior Noise in Buildings Generated by Underground Rail Traffic, Journal of Sound and Vibration, 2006, 293, $680-690$.

[3] G. Degrande, D.Clouteau, R.Othman, et al. A Numerical Model for Structure-borne Vibrations from Underground Railway Traffic Based on a Periodic Finite Element-boundary Element Formulation[J]. Journal of Sound and Vibration, 2006, 293, $645-666$.

[4] P. Fiala, G.Degrande, F.Augusztinovicz. Numerical Modeling of Structure-borne Noise and Vibration in Buildings Due to Surface Rail traffic[J]. Journal of Sound and Vibration, 2007, 301, 718-738 .

[5] Kurzweil, L.G. Structure-borne Noise and Vibration from Underground Rail Systems[J]. Journal of Sound and Vibration, 1979, 66( 3),363 -370.

[6] SHEN Daoming. Prediction, Evaluation and Experiment Study on Ground-borne Vibration and Noise Induced by Subway[D]. Shanghai: Tongji University, 2012. ( in Chinese)

[7] SHEN Daoming, ZHANG Laidong, XUE Songtao. Experimental investigation on charateristics and evaluation indexes of ground-borne noise induced by subway[J]. Joural of Civil, Architectural \& Environmental Engineering, 201335(4):130-135. ( in Chinese)

[8] ZHANG Haibin, JIANG Weikang, WANG Quan. Experimental investigation on noise radiation characteristic of urban transit train at moderate and low speed[J]. Joural of Vibration and Shock,2010,29(11),83-86. ( in Chinese)

[9] Xingwen HE. Analytical Approaches to Dynamic Issues Related to High-Speed Railway Bridge-Train Interaction System[J]. Japan[D]. 2007.

[10] Peter FIALA M . S. c.E. E. Development of a Numerical Model for the Prediction of Structure-borne Noise and Vibration in Buildings. Department of Telecommunications[D]. 2008, 53- 64. 